\title{
Transient-to-Digital Converter for System-Level Electrostatic Discharge Protection in CMOS ICs
}

\author{
Ming-Dou Ker, Fellow, IEEE, and Cheng-Cheng Yen, Student Member, IEEE
}

\begin{abstract}
A new on-chip $R C$-based transient detection circuit for system-level electrostatic discharge (ESD) protection is proposed, which can detect fast electrical transients during the systemlevel ESD test. A novel on-chip transient-to-digital converter composed of four $R C$-based transient detection circuits and four different $\boldsymbol{R C}$ filter networks has been successfully designed and verified in a 0.18- $\mu \mathrm{m}$ CMOS process with $3.3-\mathrm{V}$ devices. The output digital thermometer codes of the proposed on-chip transient-to-digital converter correspond to different ESD voltages under system-level ESD tests. The proposed on-chip transient-to-digital converter can be further combined with firmware cooperation to provide an effective solution to solve the system-level ESD protection issue in microelectronic systems equipped with CMOS ICs.
\end{abstract}

Index Terms-Converter, detection circuit, electromagnetic compatibility (EMC), electrostatic discharge (ESD), ESD protection circuit, system-level ESD test.

\section{INTRODUCTION}

$\mathbf{E}$ LECTROSTATIC discharge (ESD) has become one major reliability issue in CMOS IC products. Especially in the advanced CMOS technologies, the scaled-down processes greatly degrade the ESD robustness of CMOS ICs [1]-[3]. In component-level ESD tests, four ESD stress modes are specified at I/O pins with respect to the grounded $V_{\mathrm{DD}}$ or $V_{\mathrm{SS}}$ pins [4], [5]. In order to meet the required component-level ESD robustness, the input or output ESD protection circuits are located near to the input or output pads to bypass ESD current from the stressed pins to the grounded $V_{\mathrm{DD}}$ or $V_{\mathrm{SS}}$ pins [6], [7]. In order to further avoid unexpected damage in internal circuits under pin-to-pin and $V_{\mathrm{DD}}$-to- $V_{\mathrm{SS}}$ ESD stress conditions, the power-rail ESD clamp circuits are designed to locate between the $V_{\mathrm{DD}}$ and $V_{\mathrm{SS}}$ power lines of CMOS ICs to efficiently discharge ESD current [8]. Therefore, on-chip ESD protection circuits can successfully improve the component-level ESD robustness of CMOS ICs.

Recently, the reliability issue of system-level ESD events is attracting more attention in state-of-the-art circuits and systems [9]. This tendency results from not only the progress

Manuscript received May 12, 2008; revised September 23, 2008. First published April 28, 2009; current version published August 21, 2009. This work was supported in part by the National Science Council (NSC), Taiwan, under Contract NSC 97-2221-E-009-170, in part by the Ministry of Economic Affairs, Taiwan, under Grant 97-EC-17-A-01-S1-104, and in part by Himax Technologies, Inc., Taiwan.

M.-D. Ker is with the Nanoelectronics and Gigascale Systems Laboratory, Institute of Electronics, National Chiao-Tung University, Hsinchu 30010, Taiwan, and also with the Department of Electronic Engineering, I-Shou University, Kaohsiung 84041, Taiwan (e-mail: mdker@ieee.org).

C.-C. Yen is with the Nanoelectronics and Gigascale Systems Laboratory, Institute of Electronics, National Chiao-Tung University, Hsinchu 30010, Taiwan.

Color versions of one or more of the figures in this paper are available online at http://ieeexplore.ieee.org.

Digital Object Identifier 10.1109/TEMC.2009.2018124
TABLE I

ClassificATION OF System-LeVEl ESD TeSt LEVELS

\begin{tabular}{|c|c|c|c|}
\hline \multicolumn{2}{|c|}{ Contact Discharge } & \multicolumn{2}{c|}{ Air Discharge } \\
\hline Level & $\begin{array}{c}\text { Test Voltage } \\
(\mathrm{kV})\end{array}$ & Level & $\begin{array}{c}\text { Test Voltage } \\
(\mathrm{kV})\end{array}$ \\
\hline 1 & \pm 2 & 1 & \pm 2 \\
\hline 2 & \pm 4 & 2 & \pm 4 \\
\hline 3 & \pm 6 & 3 & \pm 8 \\
\hline 4 & \pm 8 & 4 & \pm 15 \\
\hline $\mathrm{X}$ & $\begin{array}{c}\text { Specified by } \\
\text { Customer }\end{array}$ & $\mathrm{X}$ & $\begin{array}{c}\text { Specified by } \\
\text { Customer }\end{array}$ \\
\hline
\end{tabular}

of more integrated functions into a single chip but also from the strict requirements of reliability test standards, such as the system-level ESD test standard of IEC 61000-4-2 [10]. There are four test levels defined in the standard, as shown in Table I. The level " $X$ " is an open level, which is specified by customers in their applications. According to Table I, the electrical/electronic products can be required to achieve different immunity test levels. For example, if microelectronic products are required to achieve the "level 4" in the IEC 61000-4-2 test standard, the equipment under test (EUT) should sustain the ESD level of $\pm 8 \mathrm{kV}( \pm 15 \mathrm{kV})$ under contact discharge (air discharge) test mode. Such high-energy ESD-induced noise often causes damage or malfunction to CMOS ICs inside the EUT. It has been reported that some CMOS ICs are very susceptible to systemlevel ESD stress [11]-[13], even though they have passed the component-level ESD specifications such as the human body model (HBM) of $\pm 2 \mathrm{kV}$, the machine model (MM) of $\pm 200 \mathrm{~V}$, and the charged device model (CDM) of $\pm 1 \mathrm{kV}$. Componentlevel ESD tests often cause physical damage in a chip. For microelectronic systems with CMOS ICs, system-level ESD tests often cause soft errors, including upset or locked states in the system. System-level ESD stress on microelectronic systems is more severe than component-level ESD stress in system applications. Typical on-chip ESD protection circuits in CMOS ICs can protect the internal circuits against ESD damage, but they cannot release the locked or frozen states in the microelectronic system under system-level ESD tests.

To evaluate the performance of electrical/electronic equipment subjected to electromagnetic compatibility (EMC) regulation, performing the system-level ESD test for the electrical/ electronic equipment is necessary. For example, a notebook under the system-level ESD test in the air discharge test mode is shown in Fig. 1. During such a system-level ESD test, 


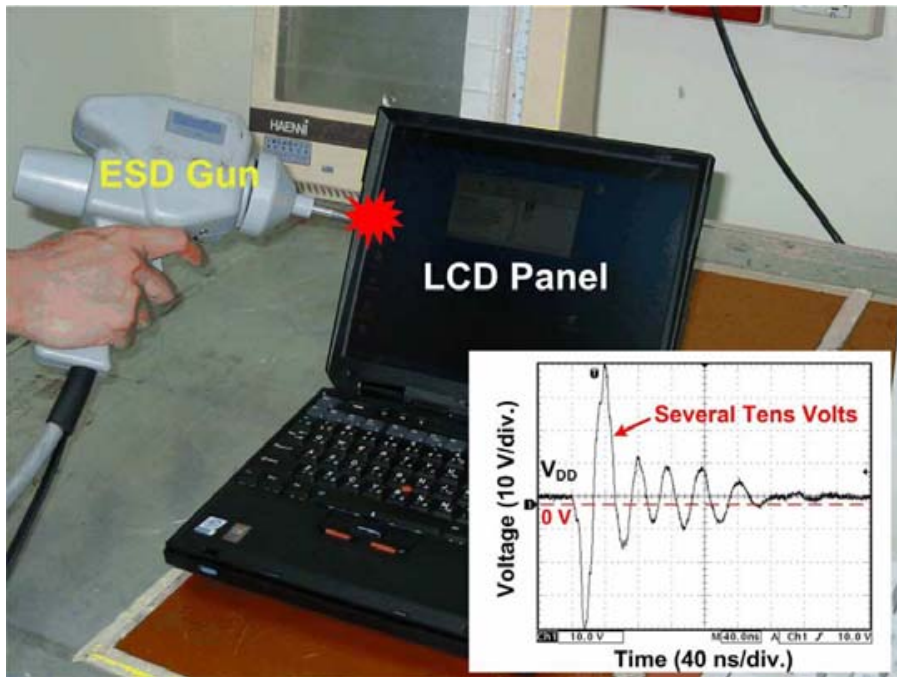

Fig. 1. System-level ESD test on a notebook with air discharge mode according to the IEC 61000-4-2 international standard. The inset depicts a typical measured waveform of the transient noise voltage on the power pin of CMOS ICs in the EUT under the system-level ESD test.

electromagnetic interference (EMI) coming from ESD will be coupled into the driver ICs of the liquid crystal display (LCD) panel. The inset in Fig. 1 depicts a typical measured ESDgenerated voltage waveform coupled to the power pins of CMOS ICs in the EUT under the system-level ESD test. During systemlevel ESD test, the power and ground lines of the IC in microelectronic products no longer maintained their normal voltage levels, but an underdamped sinusoidal voltage with the amplitude of several tens volts occurred, as shown in the inset in Fig. 1. This ESD-generated transient voltage is quite large (with an amplitude of several tens to hundreds of volts) and fast (with a period of several tens of nanoseconds) and randomly exists on power, ground, or I/O pins of the ICs inside the microelectronic system. Such a high-voltage-level fast transient causes the CMOS ICs to be upset or frozen after the system-level ESD zapping [13]. Such fast transients can even cause serious reliability events, such as transient-induced latchup (TLU) in CMOS ICs [9].

To meet the system-level ESD specifications, two useful methods have been reported and investigated [14]-[16]. One effective method is to add some discrete noise-decoupling components or board-level noise filters into the CMOS IC products to decouple, bypass, or absorb the electrical transient voltage (energy) under system-level ESD test [14], [15]. The noise filter networks, such as the capacitor filter, ferrite bead, transient voltage suppressor (TVS), $L C$-like (second order), and $\pi$-section (third order) filters, can be used to improve the system-level ESD immunity. The system-level ESD immunity of CMOS ICs under system-level ESD tests can be greatly improved by choosing proper noise filter networks. The other method to improve the system-level ESD immunity of CMOS ICs is to regularly check for abnormal system conditions by using an external hardware timer, such as retriggerable monostable multivibrator [16]. However, with more integrated functions going into system-onchip (SOC) designs, such additional discrete noise-bypassing
TABLE II

ReCOMMENDED Classifications OF SySTEM-LEVEL ESD TEST RESUltS

\begin{tabular}{|l|l|}
\hline Criterion & \multicolumn{1}{|c|}{ Recommended Classification } \\
\hline Class A & $\begin{array}{l}\text { Normal performance within limits specified by the manufacturer, } \\
\text { requestor or purchaser. }\end{array}$ \\
\hline Class B & $\begin{array}{l}\text { Temporary loss of function or degradation of performance which } \\
\text { ceases after the disturbance ceases, and from which the } \\
\text { equipment under test recovers its normal performance, without } \\
\text { operator intervention. (Automatic Recovery) }\end{array}$ \\
\hline Class C & $\begin{array}{l}\text { Temporary loss of function or degradation of performance, the } \\
\text { correction of which requires operator intervention. } \\
\text { (Manual Recovery) }\end{array}$ \\
\hline Class D & $\begin{array}{l}\text { Loss of function or degradation of performance which is not } \\
\text { recoverable, owing to damage to hardware or software, or loss } \\
\text { of data. }\end{array}$ \\
\hline
\end{tabular}

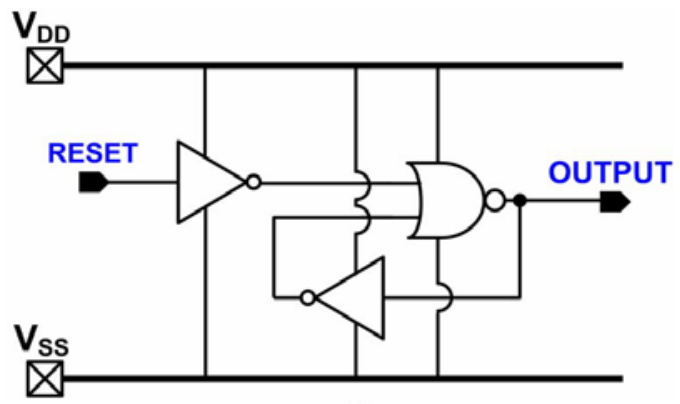

(a)

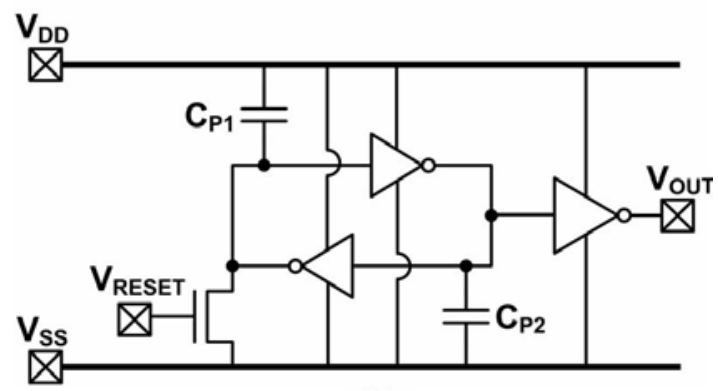

(b)

Fig. 2. Previous on-chip transient detection circuits composed of (a) latch circuit and (b) capacitors $\left(C_{\mathrm{P} 1}\right.$ and $\left.C_{\mathrm{P} 2}\right)$ to enhance the detection sensitivity.

components may not be integrated into a single chip due to the limitation of chip area and the substantial increase in the total cost of microelectronic products. In the IEC 61000-4-2 standard, four recommended classifications of system-level ESD test results have been defined, as listed in Table II. In order to solve the locked or frozen states caused by system-level ESD zapping, microelectronic products system functions can manually reset with operator intervention, which meets "class C" criterion defined in the standard. However, most microelectronic products are required at least to automatically recover the system functions without operator intervention to meet "class B" criterion. Therefore, to meet high system-level ESD specifications for microelectronic system products, the chip-level solutions that can help the microelectronic system to execute autorecovery procedure without using additional discrete noise-decoupling components on the printed circuit board (PCB) are highly desired by the IC industry [17], [18].

In previous work, two on-chip transient detection circuits have been proposed to detect transient noise, as shown in Fig. 2(a) and (b). The circuit structure in Fig. 2(a) is composed of a 


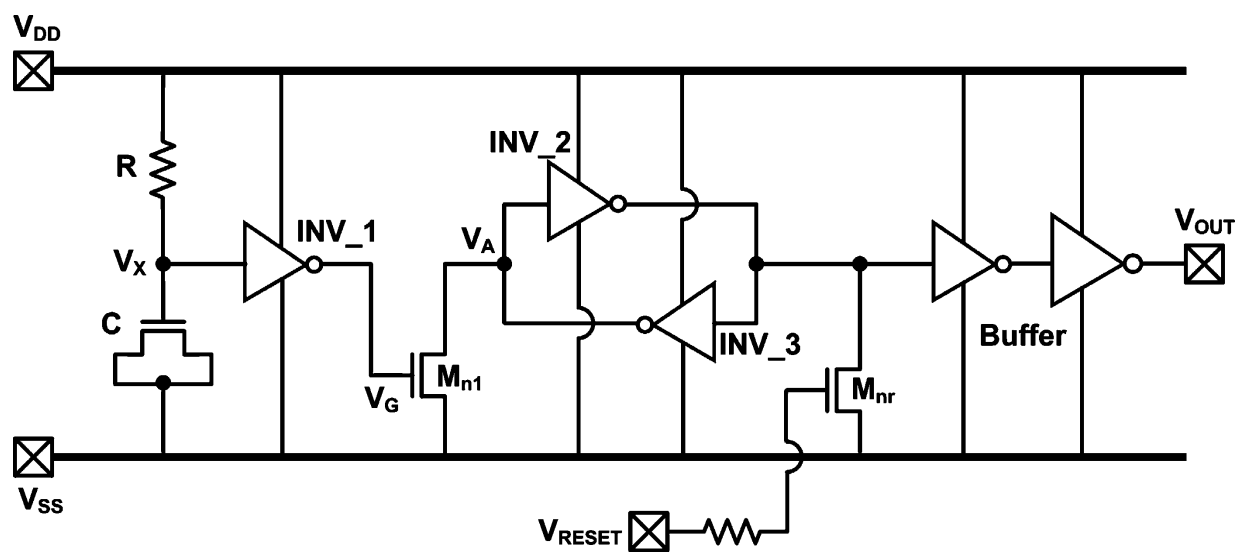

Fig. 3. New proposed on-chip $R C$-based transient detection circuit.

latch circuit [13]. The detection sensitivity is adjusted by the device ratio between PMOS and NMOS in the latch circuit. The modified design concept in Fig. 2(b) is realized with additional capacitors $\left(C_{\mathrm{P} 1}\right.$ and $\left.C_{\mathrm{P} 2}\right)$ located between $V_{\mathrm{DD}} / V_{\mathrm{SS}}$ power lines and the input/output nodes of latch circuit to enhance its detection function [17]. However, for both previous designs, the transient detection circuits cannot distinguish the transient noise levels under system-level ESD tests with different ESD voltages.

In this paper, a new on-chip $R C$-based transient detection circuit is proposed to detect the fast electrical transient under a system-level ESD test. By using a longer time delay in the $R C$ circuit under system-level ESD tests, the proposed new on-chip $R C$-based transient detection circuit can memorize the occurrence of system-level ESD events. The circuit operation to detect different positive and negative fast electrical transients has been investigated by HSPICE simulation and verified in silicon. The TLU measurement method [19] and the system-level ESD gun [20] are used to evaluate the detection function of the proposed on-chip $R C$-based transient detection circuit under system-level ESD test. A novel on-chip transient-to-digital converter composed of $R C$-based transient detection circuits is proposed for the first time in the literature to detect the fast electrical transients and convert them to digital thermometer codes under systemlevel ESD stresses. The experimental results in a $0.18-\mu \mathrm{m}$ CMOS process with $3.3-\mathrm{V}$ devices have verified that the proposed on-chip transient-to-digital converter can successfully convert the fast electrical transients with different ESD voltage levels into digital codes during system-level ESD zapping. In the future works, the proposed on-chip transient-to-digital converter can be further co-designed with firmware of self-recovery procedures to provide an effective solution against system-level ESD test in microelectronic systems equipped with CMOS ICs.

\section{II. $R C$-BASED TRANSIENT DeteCtion CiRCUIT}

\section{A. Circuit Structure}

Fig. 3 shows the proposed on-chip $R C$-based transient detection circuit. The $R C$-based circuit structure is designed to realize the transient detection function. The two-inverter latch (INV_2 and INV_3) is designed to memorize the logic state before and after system-level ESD stress. The NMOS $\left(M_{\mathrm{nr}}\right)$ is used to provide the initial reset function to set the initial output voltage ( $V_{\mathrm{OUT}}$ ) level to $0 \mathrm{~V}$. In Fig. 3, the node $V_{\mathrm{X}}$ is biased at $V_{\mathrm{DD}}$ and the node $V_{\mathrm{G}}$ is biased at $V_{\mathrm{SS}}$ during the normal operation condition. Under the system-level ESD stress, the ESD voltage has a fast rise time on the order of a nanosecond (ns). The voltage level of $V_{\mathrm{X}}$ has a much slower voltage response than the voltage level at $V_{\mathrm{DD}}$ because the $R C$ circuit has a time constant on the order of a microsecond $(\mu \mathrm{s})$. Due to the longer delay of the voltage increase at the node $V_{\mathrm{X}}$, the PMOS device in the inverter1 (INV_1) can be turned on by the overshooting ESD voltage and conducts a voltage to the node $V_{\mathrm{G}}$ to further turn on the $M_{\mathrm{n} 1}$ device. The turn-ON $M_{\mathrm{n} 1}$ device can pull down the output voltage level at the node $V_{\mathrm{A}}$. Therefore, the logic level stored in the two-inverter latch can be changed to detect the system-level ESD event. The output voltage $\left(V_{\mathrm{OUT}}\right)$ of the proposed on-chip $R C$-based transient detection circuit is finally changed from 0 to $3.3 \mathrm{~V}$ to memorize the occurrence of system-level ESD events.

\section{B. Simulation}

From the measured fast electrical transient waveforms shown in the inset in Fig. 1, the underdamped sinusoidal waveforms on $V_{\mathrm{DD}}$ and $V_{\mathrm{SS}}$ during the system-level ESD stress have been observed. Thus, a specific time-dependent voltage source given by

$$
V(t)=V_{0}+V_{a} \sin \left(2 \pi f\left(t-t_{d}\right)\right) \exp \left(-\left(t-t_{d}\right) D_{a}\right)
$$

is used to generate an underdamped sinusoidal voltage on the power lines of the proposed on-chip $R C$-based transient detection circuit in the simulation. With the proper parameters such as the applied voltage amplitude $V_{a}$, initial de voltage $V_{o}$, damping factor $D_{a}$, frequency $f$, and time delay $t_{d}$, the underdamped sinusoidal voltage can be used for simulation. In the HSPICE simulation with positive or negative underdamped sinusoidal waveforms, the same parameters of $D_{a}=2 \times 10^{7} \mathrm{~s}^{-1}$, $f=50 \mathrm{MHz}$, and $t_{d}=500 \mathrm{~ns}$ are used (which corresponds to the measured transient waveform in the inset in Fig. 1). The only difference is that the positive $V_{a}$ is for a positive-going underdamped sinusoidal waveform and the negative $V_{a}$ is for a negative-going underdamped sinusoidal waveform. In addition, 


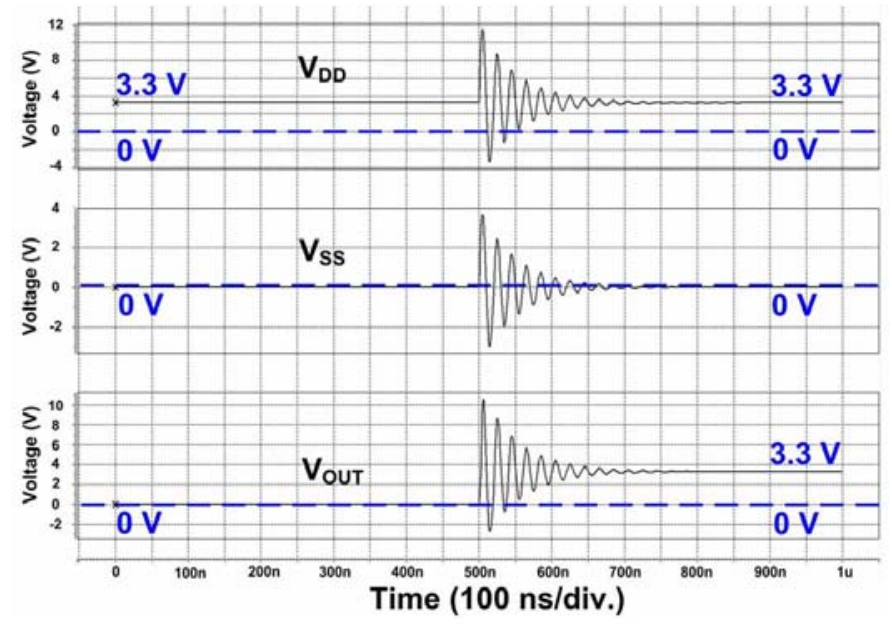

(a)

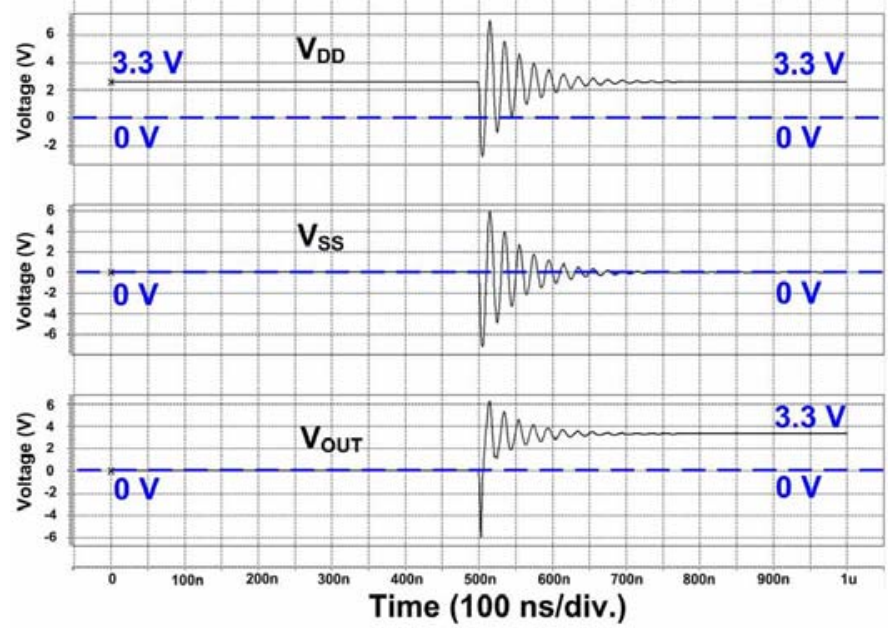

(b)

Fig. 4. Simulated $V_{\mathrm{DD}}, V_{\mathrm{SS}}$, and $V_{\mathrm{OUT}}$ waveforms of the proposed onchip $R C$-based transient detection circuit under system-level ESD test with (a) positive-going and (b) negative-going, overshooting voltages coupled on $V_{\mathrm{DD}}$ and $V_{\mathrm{SS}}$.

$V_{o}$ of 3.3 and $0 \mathrm{~V}$ are used as the initial de voltages on the $V_{\mathrm{DD}}$ and $V_{\mathrm{SS}}$, respectively, in the simulation.

Under the system-level ESD tests, the transient disturbances on $V_{\mathrm{SS}}$ line inside the IC differs from the PCB ground due to bonding effect in the package and various transmission line effects along the PCB tracks. Therefore, different transient disturbances on power lines of CMOS ICs can be induced during system-level ESD tests.

The simulated $V_{\mathrm{DD}}, V_{\mathrm{SS}}$, and $V_{\mathrm{OUT}}$ waveforms of the proposed on-chip $R C$-based transient detection circuit with positive-going and negative-going underdamped sinusoidal voltage on $V_{\mathrm{DD}}$ and $V_{\mathrm{SS}}$ lines are shown in Fig. 4(a) and (b), respectively. The positive-going (negative-going) underdamped sinusoidal voltage with amplitude of $+8 \mathrm{~V}(-8 \mathrm{~V})$ is used to simulate the positive (negative) ESD stress under the systemlevel ESD test. Under ESD stress, $V_{\mathrm{DD}}$ begins to change rapidly from normal operation voltage level of $3.3 \mathrm{~V}$. $V_{\mathrm{OUT}}$ is disturbed simultaneously during the simulated ESD-induced disturbance. During this period, the proposed on-chip $R C$-based transient de-

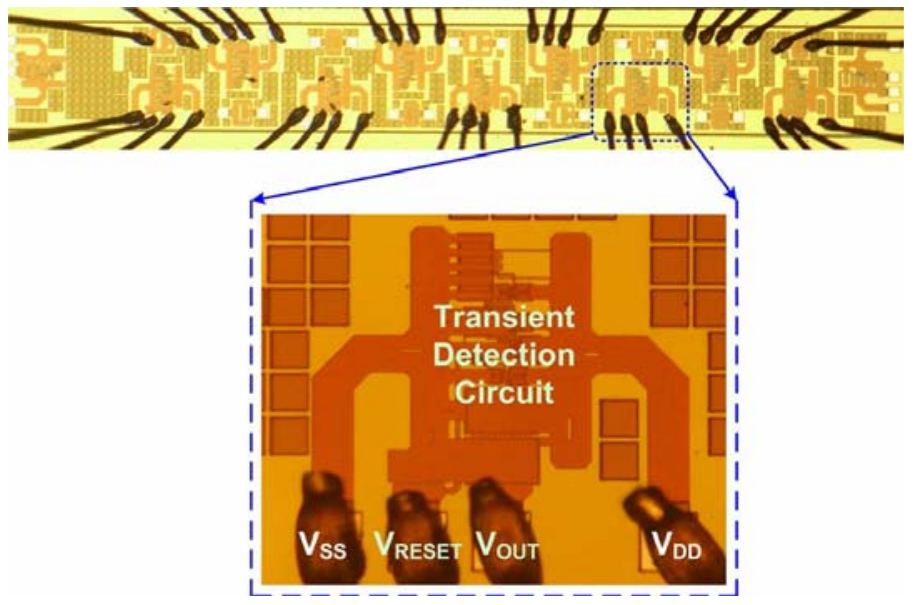

Fig. 5. Die photo of the proposed on-chip $R C$-based transient detection circuits with different $R C$ values in layout.

tection circuit can detect the occurrence of transient disturbance. As a result, after $V_{\mathrm{DD}}$ finally returns to its normal voltage level of $3.3 \mathrm{~V}, V_{\text {OUT }}$ will be both changed from 0 to $3.3 \mathrm{~V}$, as shown in Fig. 4(a) and (b).

In this study, a specific time-dependent underdamped sinusoidal source is used to verify the detection functions of the proposed on-chip transient detection circuit in HSPICE simulation. In advance, the interaction between the impedance of the ESD generator and the proposed circuit can be taken into HSPICE simulation to further optimize the circuit operation and design to detect system-level ESD events.

The proposed on-chip $R C$-based transient detection circuit has been designed and fabricated in a $0.18-\mu \mathrm{m}$ 1P5M CMOS process with $3.3-\mathrm{V}$ devices. The fabricated chip in a package for system-level ESD test is shown in Fig. 5, where the silicon area of the proposed on-chip transient detection circuit is $266 \mu \mathrm{m} \times 236 \mu \mathrm{m}$. The TLU measurement method and the system-level ESD gun are used to evaluate the detection function of the proposed on-chip $R C$-based transient detection circuit under system-level ESD test.

\section{TLU TEST}

\section{A. Measurement Setup}

A TLU test has been used to investigate the susceptibility of device under test (DUT) to the noise transient or glitch on the power lines under normal circuit operating condition. The component-level TLU measurement setup with bipolar trigger waveform can accurately simulate the ESD-induced noises on the power lines of CMOS ICs under system-level ESD test [19]. The measurement setup for TLU test is shown in Fig. 6. The charging voltage $V_{\text {Charge }}$ has two different polarities, which are positive $\left(V_{\text {Charge }}>0\right)$ and negative $\left(V_{\text {Charge }}<0\right)$. The positive (negative) $V_{\text {Charge }}$ can generate the positive-going (negativegoing) bipolar trigger noise on the power pins of the DUT. A 200-pF capacitor used in the MM ESD test is employed as the charging capacitor. The proposed on-chip $R C$-based transient detection circuit shown in Fig. 3 is placed as the DUT in Fig. 6. The supply voltage of $3.3 \mathrm{~V}$ is used as $V_{\mathrm{DD}}$ and the noise trigger 


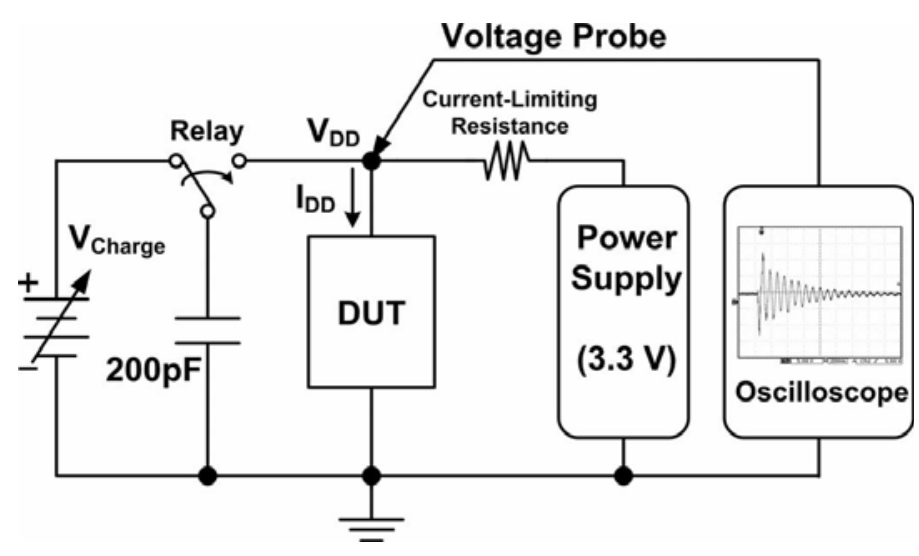

Fig. 6. Measurement setup for TLU [19].

source is directly connected to DUT through the relay in the measurement setup. The current-limiting resistance is used to avoid electrical overstress (EOS) damage in the DUT under a high-current latchup state. The voltage and current waveforms on the DUT (at $V_{\mathrm{DD}}$ node) after the TLU test are monitored by the oscilloscope.

\section{B. Measurement Results}

Fig. 7(a) and (b) shows the measured $V_{\mathrm{DD}}$ and $V_{\mathrm{OUT}}$ transient responses of the proposed on-chip $R C$-based transient detection circuit under the TLU test with $V_{\text {Charge }}$ of +9 and $-2 \mathrm{~V}$, respectively. As shown in Fig. 7(a), under the TLU test with $V_{\text {Charge }}$ of $+9 \mathrm{~V}, V_{\mathrm{DD}}$ begins to increase rapidly from $3.3 \mathrm{~V}$. $V_{\mathrm{OUT}}$ is disturbed simultaneously with positive underdamped sinusoidal voltages on the $V_{\mathrm{DD}}$ power line. After the TLU test with an initial $V_{\text {Charge }}$ of $+9 \mathrm{~V}$, the output $\left(V_{\text {OUT }}\right)$ of the proposed on-chip $R C$-based transient detection circuit is changed from 0 to $3.3 \mathrm{~V}$. As shown in Fig. 7(b), under the TLU test with $V_{\text {Charge }}$ of $-2 \mathrm{~V}$, $V_{\mathrm{DD}}$ begins to decrease rapidly from $3.3 \mathrm{~V}$. $V_{\mathrm{OUT}}$ is disturbed simultaneously with negative underdamped sinusoidal voltages on $V_{\mathrm{DD}}$ power line. After the TLU test with an initial $V_{\mathrm{Charge}}$ of $-2 \mathrm{~V}$, the output voltage ( $V_{\mathrm{OUT}}$ ) of the proposed on-chip $R C$-based transient detection circuit is increased from $0 \mathrm{~V}$ to a stable voltage of $3.3 \mathrm{~V}$.

From the TLU test results, the proposed on-chip $R C$-based transient detection circuit can successfully detect fast electrical transients on the $V_{\mathrm{DD}}$ power line. With positive and negative underdamped sinusoidal voltages on power lines, the output voltages $\left(V_{\mathrm{OUT}}\right)$ of the proposed on-chip $R C$-based transient detection circuit are changed from $0 \mathrm{~V}$ to a stable voltage of $3.3 \mathrm{~V}$ after the transition.

\section{System-LEVEL ESD TeST}

\section{A. Measurement Setup}

In the IEC 61000-4-2 standard [10], the equipment specifications for different testing modes have been defined. For tabletop equipment, the measurement setup should consist of a wooden table, standing on the ground reference plane (GRP). Horizontal or vertical coupling planes (VCPs) should be placed on the table. An insulating plane of $0.5 \mathrm{~mm}$ thickness should be inserted

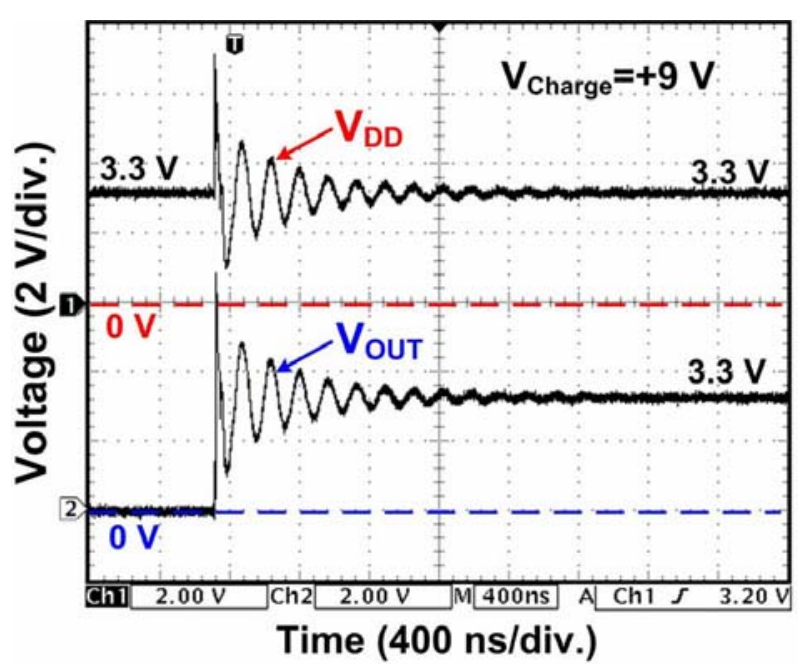

(a)

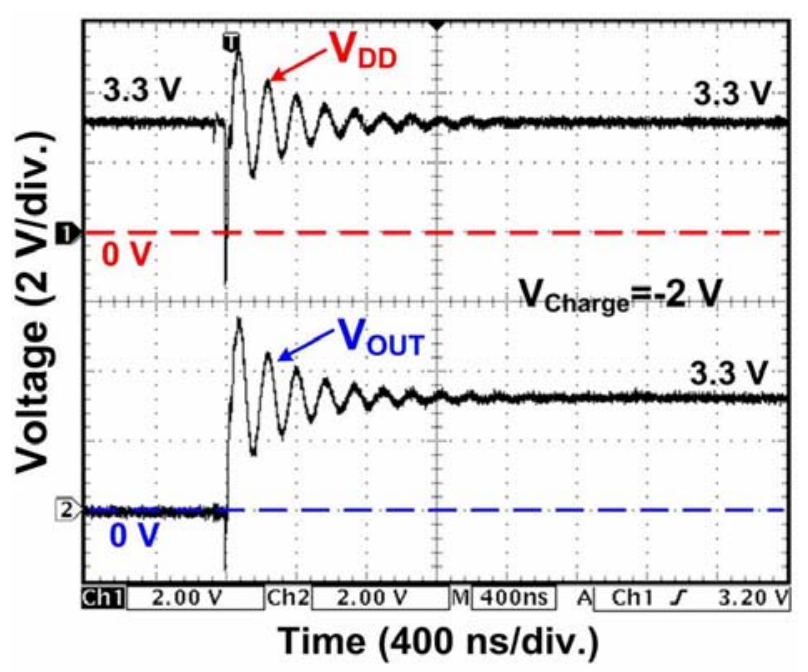

(b)

Fig. 7. Measured $V_{\mathrm{DD}}$ and $V_{\mathrm{OUT}}$ waveforms on the proposed on-chip $R C$ based transient detection circuit under TLU test with $V_{\mathrm{Charge}}$ of (a) $+9 \mathrm{~V}$ and (b) $-2 \mathrm{~V}$.

between the EUT/cables and horizontal coupling plane (HCP). For floor-standing equipment, the EUT and cables should be isolated from the GRP by an insulating support about $0.1 \mathrm{~m}$ thick. Any mounting feet associated with the EUT should be remained in the place. The VCP is used for indirect application of discharges.

In the IEC 61000-4-2 standard [10], two test modes have been also specified, which are the air discharge test mode and the contact discharge test mode. Contact discharge is further divided into direct discharge to the system under test, and indirect discharge to horizontal or VCPs. Fig. 8 shows the standard measurement setup of the system-level ESD test with the indirect contact discharge test mode. The HCP is connected to the GRP with bleeder wire with two $470-\mathrm{k} \Omega$ resistors in series mounded on both ends of the wire. When the ESD gun zaps the HCP, the EMI coming from ESD will be coupled into all CMOS ICs inside EUT. The power lines of CMOS ICs inside EUT will be disturbed by the ESD-coupled energy. 


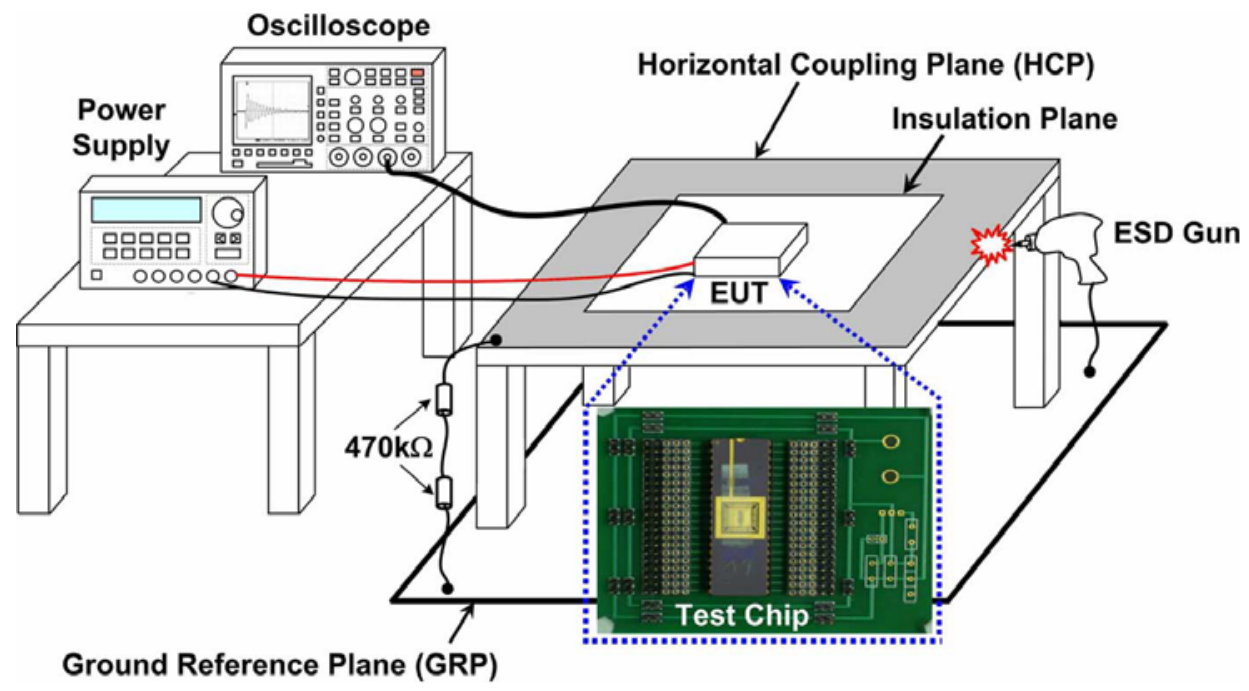

Fig. 8. Measurement setup for a system-level indirect contact ESD zapping to the horizontal coupling plate in the indirect contact discharge test mode [10] to evaluate the detection performance of the proposed on-chip $R C$-based transient detection circuit.

With such a standard measurement setup, the circuit performance of the proposed on-chip $R C$-based transient detection circuit under system-level ESD tests can be evaluated. By using the digital oscilloscope, the transient responses on power lines of CMOS IC products can be recorded and analyzed. Before each system-level ESD zapping, the initial output voltage ( $\left.V_{\mathrm{OUT}}\right)$ of the proposed on-chip $R C$-based transient detection circuit is reset to $0 \mathrm{~V}$. After each system-level ESD zapping, the output voltage $\left(V_{\mathrm{OUT}}\right)$ level is measured to check the final voltage level and verify the detection function. Thus, the circuit performance of the proposed on-chip $R C$-based transient detection circuit can be directly evaluated with this measurement setup.

\section{B. Measurement Results}

The measured $V_{\mathrm{DD}}$ and $V_{\mathrm{OUT}}$ waveforms of the proposed on-chip $R C$-based transient detection circuit under a systemlevel ESD test with the ESD voltage of +0.2 and $-0.2 \mathrm{kV}$ zapping on the HCP are shown in Fig. 9(a) and (b), respectively. Under system-level ESD zapping conditions, $V_{\mathrm{DD}}$ line is no longer maintained at the normal voltage level of $+3.3 \mathrm{~V}$. Meanwhile, $V_{\text {OUT }}$ begins to change under such a high-energy ESD stress. During the fast transient disturbance, $V_{\mathrm{DD}}$ and $V_{\mathrm{OUT}}$ are influenced simultaneously. Finally, the output voltage of the proposed on-chip $R C$-based transient detection circuit has been changed from 0 to $3.3 \mathrm{~V}$. Therefore, the proposed on-chip $R C$-based transient detection circuit can sense the fast electrical transient on the power lines and memorize the occurrence of system-level ESD events. The experimental result shown in Fig. 9(a) [Fig. 9(b)] is consistent with the HSPICE simulation results in Fig. 4(a) [Fig. 4(b)].

\section{Transient-TO-Digital CONVERTER}

\section{A. Transient Detection Circuit With On-Chip Noise Filter Network}

It has been shown that noise filter networks can enhance immunity of CMOS ICs to system-level ESD test by decoupling,

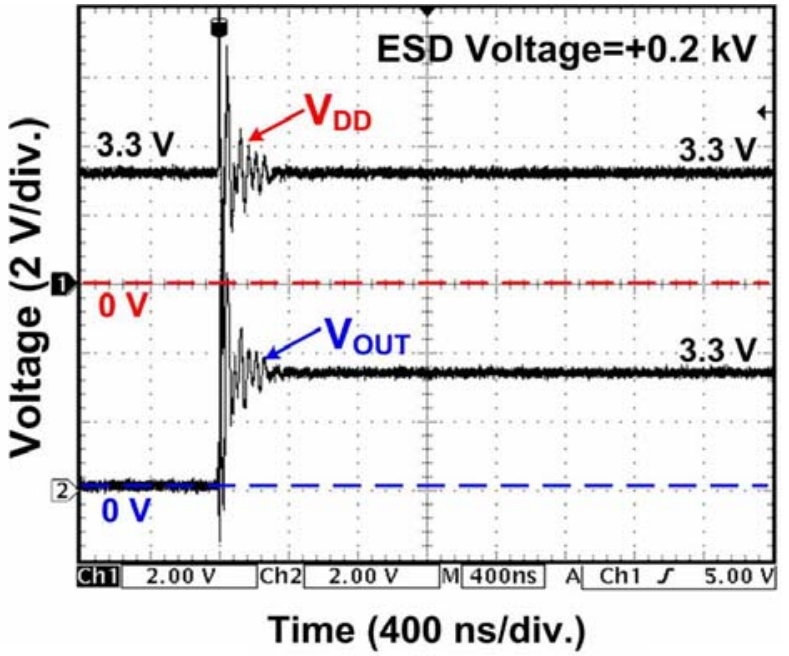

(a)

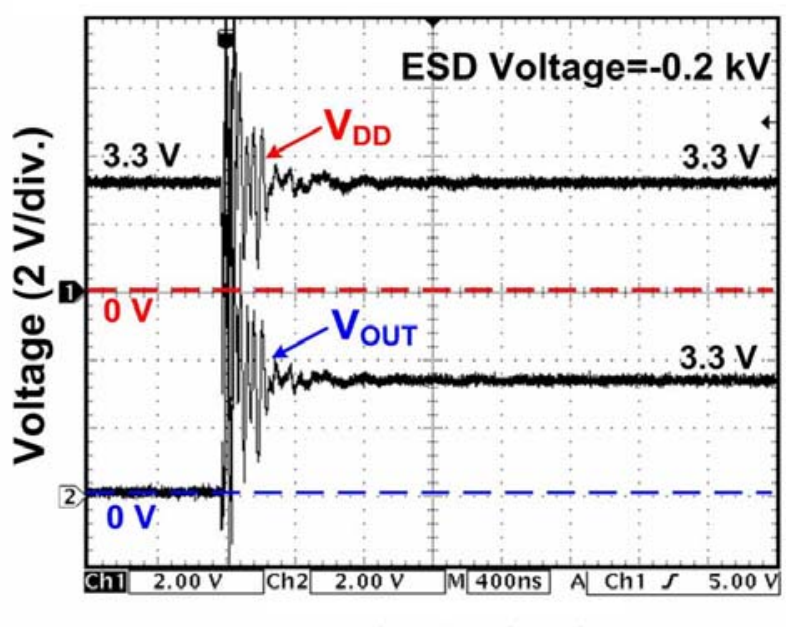

Time (400 ns/div.)

(b)

Fig. 9. Measured $V_{\mathrm{DD}}$ and $V_{\mathrm{OUT}}$ transient voltage waveforms of the proposed on-chip $R C$-based transient detection circuit under system-level ESD test with ESD voltage of (a) $+0.2 \mathrm{kV}$ and (b) $-0.2 \mathrm{kV}$. 


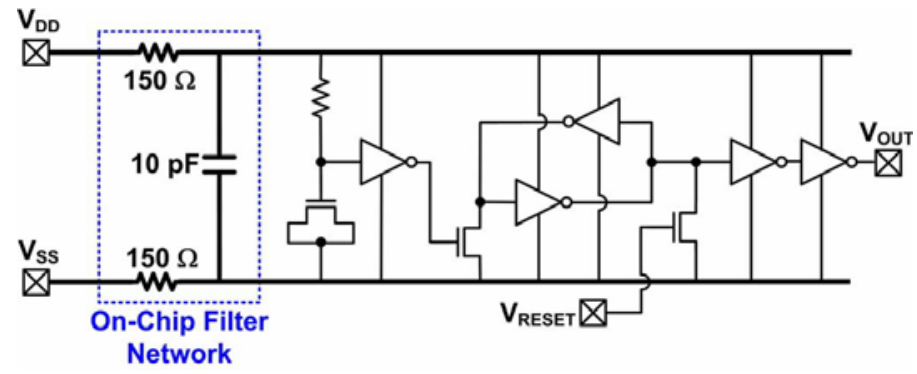

Fig. 10. On-chip $R C$-based transient detection circuit combined with a noise filter network.

bypassing, or absorbing ESD-induced noise voltage (energy). It has also been reported that the noise filter networks have strong impact to the parameters of the underdamped sinusoidal voltage such as transient peak voltage, damping frequency, and damping factor [15]. Fig. 10 shows the on-chip $R C$-based transient detection circuit combined with a $R C$ filter network, which is realized with one decoupling capacitor and two resistors with equal value to provide the noise filter function during systemlevel ESD stresses. The $R C$ noise filter network can suppress the transient peak voltages on $V_{\mathrm{DD}}$ and $V_{\mathrm{SS}}$, which influences positive and negative system-level ESD voltages to cause transition at the output ( $V_{\mathrm{OUT}}$ ) of the proposed on-chip $R C$-based transient detection circuit. Therefore, in combination with different $R C$ noise filter networks, the proposed on-chip $R C$-based transient detection circuit can be designed to detect different voltage levels under system-level ESD tests.

The on-chip $R C$-based transient detection circuit combined with on-chip $R C$ filter network has been designed and fabricated in a $0.18-\mu \mathrm{m} 1 \mathrm{P} 5 \mathrm{M}$ CMOS process with $3.3-\mathrm{V}$ devices.

With the aid of the on-chip filter network to reduce the noise voltage on power lines, the minimum positive system-level ESD voltage to cause transition at the output $\left(V_{\mathrm{OUT}}\right)$ of the proposed on-chip $R C$-based transient detection circuit can be significantly enhanced from $+0.2 \mathrm{kV}$ (without on-chip filter network) to $+1.8 \mathrm{kV}$ (with on-chip filter network), as shown in Fig. 11(a). Similarly, the minimum negative system-level ESD voltage to cause transition at the output ( $\left.V_{\mathrm{OUT}}\right)$ of the proposed on-chip $R C$-based transient detection circuit can be also enhanced from $-0.2 \mathrm{kV}$ (without on-chip filter network) to $-1.6 \mathrm{kV}$ (with onchip filter network), as shown in Fig. 11(b). Thus, by choosing proper capacitance and resistance, the on-chip filter network placed between $V_{\mathrm{DD}}$ and $V_{\mathrm{SS}}$ can be used to appropriately adjust the detection voltage level of the proposed on-chip $R C$-based transient detection circuit under system-level ESD test, both for the positive or the negative electrical fast transients. With different detection voltage levels, the strength of system-level ESD stress to the CMOS ICs can be converted into digital codes. Therefore, a novel transient-to-digital converter can be built up by using the proposed on-chip $R C$-based transient detection circuits with different $R C$ filter networks.

\section{B. Four-Bit Transient-to-Digital Converter}

Fig. 12 shows the proposed on-chip transient-to-digital converter. The 4-bit on-chip transient-to-digital converter consists

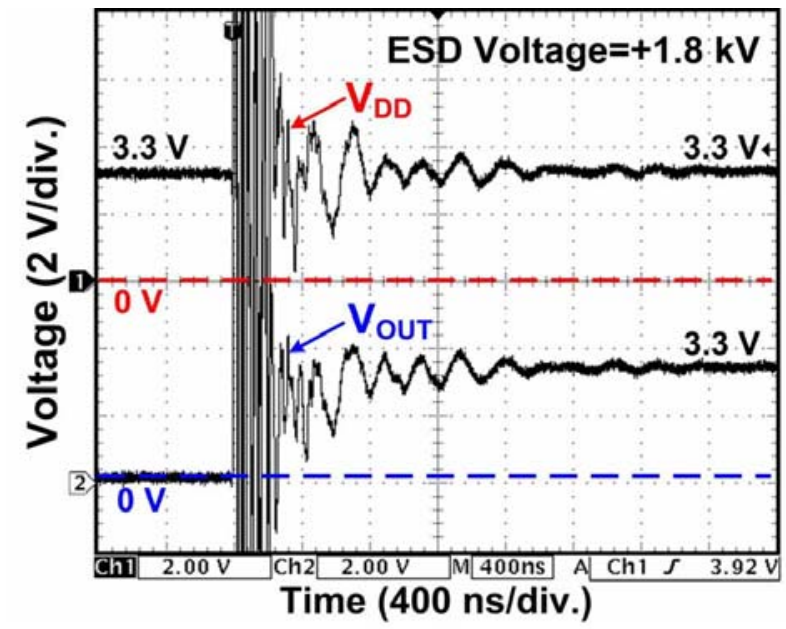

(a)

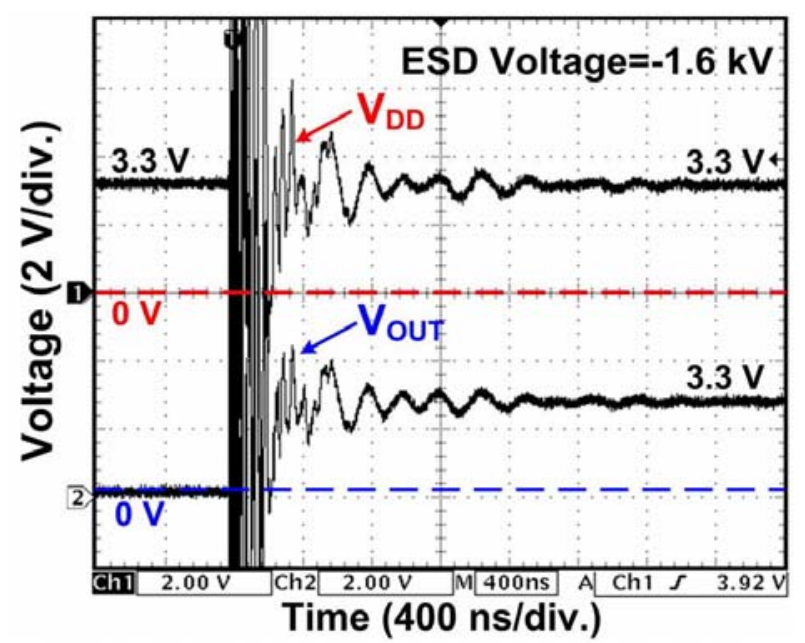

(b)

Fig. 11. Measured $V_{\mathrm{DD}}$ and $V_{\mathrm{OU}}$ transient voltage waveforms of the proposed on-chip $R C$-based transient detection circuit combined with a noise filter network under a system-level ESD test with an ESD voltage of (a) $+1.8 \mathrm{kV}$ and (b) $-1.6 \mathrm{kV}$.

of four $R C$-based transient detection circuits with four different $R C$ filter networks. With different resistance values in the filter networks, different ESD energy on $V_{\mathrm{DD}}$ and $V_{\mathrm{SS}}$ will reach each transient detection circuit. Therefore, under the system-level ESD zapping conditions with different ESD voltages, the four transient detection circuits will have different output responses. The proposed on-chip transient-to-digital converter has been designed and fabricated in a $0.18-\mu \mathrm{m} 1 \mathrm{P} 5 \mathrm{M}$ CMOS process with 3.3-V devices. The fabricated chip in a package for system-level ESD test is shown in Fig. 13(a) and (b). The silicon area of proposed on-chip 4-bit transient-to-digital converter is $1030 \mu \mathrm{m} \times$ $188.5 \mu \mathrm{m}$, as shown in Fig. 13(a). The silicon area of detection circuit to generate 1-bit output signal is $218 \mu \mathrm{m} \times 180 \mu \mathrm{m}$, as shown in Fig. 13(b).

The measured $V_{\mathrm{OUT} 1}, V_{\mathrm{OUT} 2}, V_{\mathrm{OUT} 3}$, and $V_{\mathrm{OUT}} 4$ waveforms of the proposed on-chip transient-to-digital converter under system-level ESD test with an ESD voltage of $+0.8 \mathrm{kV}$ zapping on the HCP are shown in Fig. 14(a). During the fast transient of the ESD stress, $V_{\mathrm{OUT} 1}, V_{\mathrm{OUT} 2}, V_{\mathrm{OUT} 3}$, and $V_{\mathrm{OUT} 4}$ are disturbed simultaneously during the $V_{\mathrm{DD}}$ and $V_{\mathrm{SS}}$ disturbance. Finally, $V_{\text {OUT1 }}$ will be changed from 0 to $3.3 \mathrm{~V}$ while 


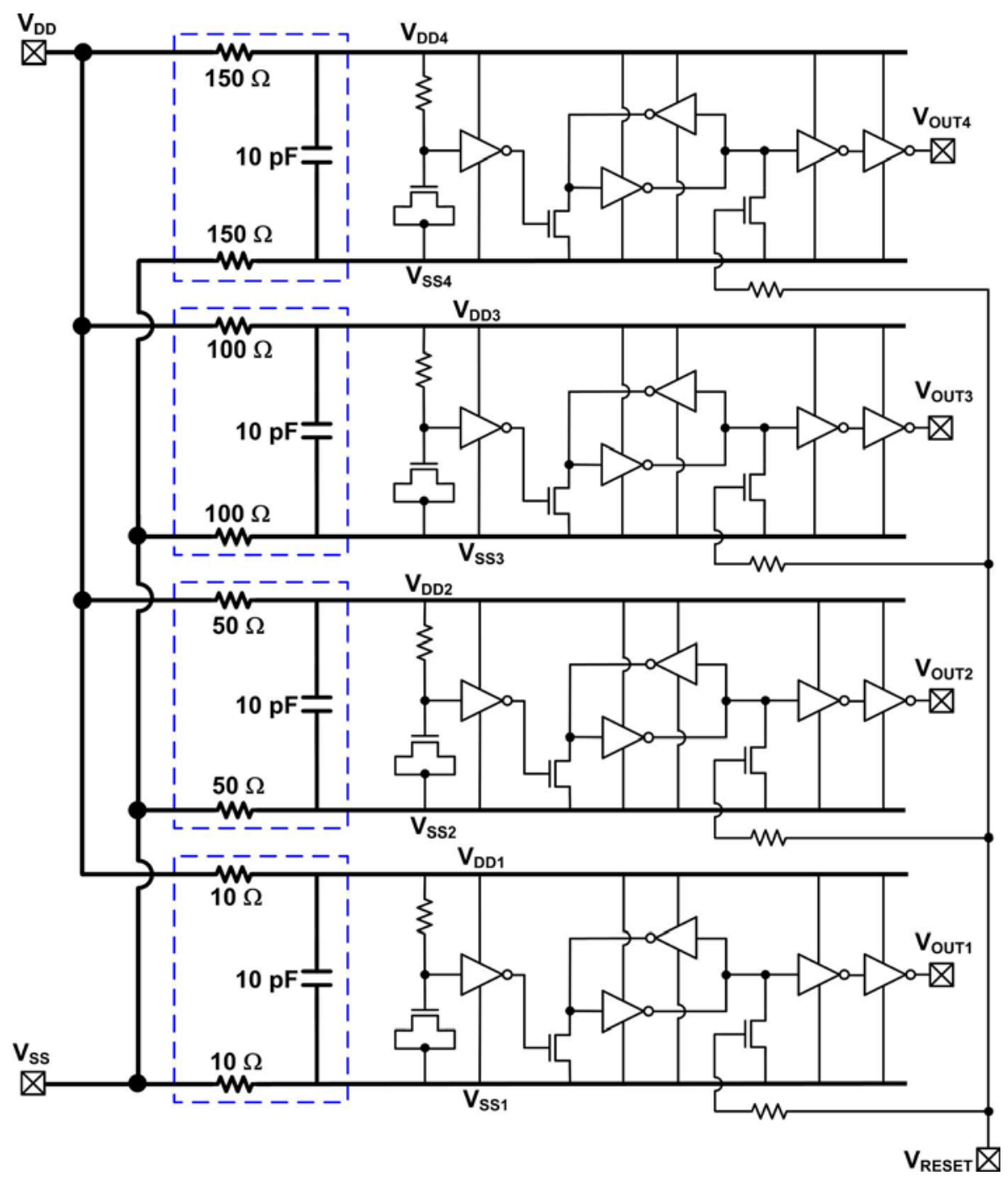

Fig. 12. Proposed on-chip 4-bit transient-to-digital converter realized with four transient detection circuits and $R C$ filter networks.

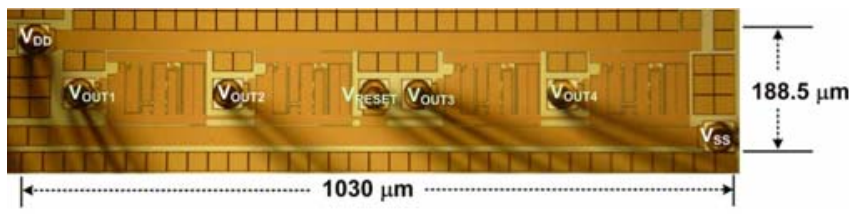

(a)

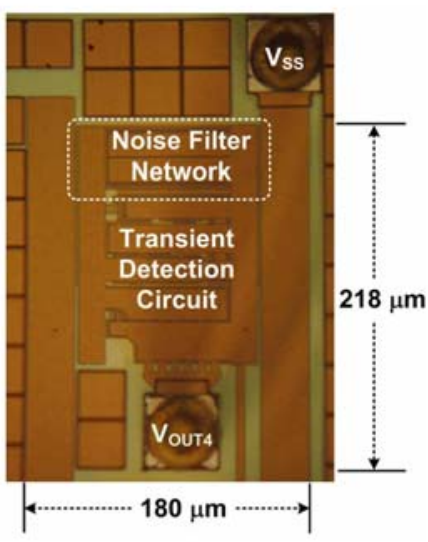

(b)

Fig. 13. Die photos of: (a) whole 4-bit transient-to-digital converter realized with four transient detection circuits and $R C$ filter networks, and (b) detection circuit to generate the $V_{\mathrm{OU}} 4$ signal.
$V_{\mathrm{OUT} 2}, V_{\mathrm{OUT} 3}$, and $V_{\mathrm{OUT} 4}$ remain $0 \mathrm{~V}$. Therefore, under a system-level ESD test with an ESD voltage of $+0.8 \mathrm{kV}$ zapping, the output voltages of the proposed on-chip transient-to-digital converter can be transferred into a digital thermometer code of "0001."

Similarly, Fig. 14(b), (c), and (d) shows the measured $V_{\mathrm{OUT} 1}, V_{\mathrm{OUT} 2}, V_{\mathrm{OUT} 3}$, and $V_{\mathrm{OUT} 4}$ waveforms of the proposed on-chip transient-to-digital converter under a system-level ESD test with ESD voltages of $+1.2,+1.8$, and $+3.1 \mathrm{kV}$ zapping on the HCP, and transferred into digital thermometer codes of "0011," "0111," and "1111," respectively.

Fig. 15 depicts the relationship between the ESD zapping voltages and the converted codes. With the proposed onchip transient-to-digital converter, different ESD voltages under system-level ESD tests can be detected and transferred into different digital thermometer codes. With a larger ESD voltage level, the digital thermometer code goes higher, as listed in Table III.

\section{FUtURE WORKS AND APPLICATIONS}

It had been reported that the hardware/firmware can be co-designed to effectively improve the system-level ESD 


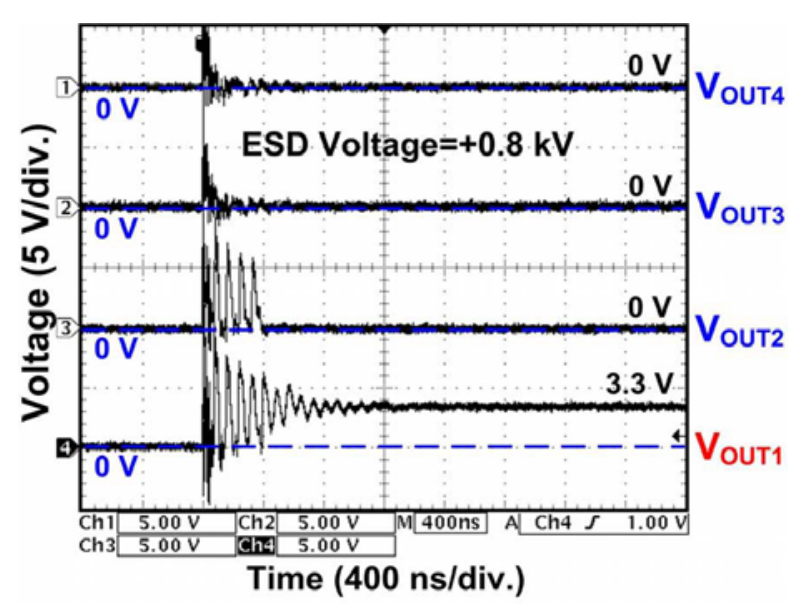

(a)

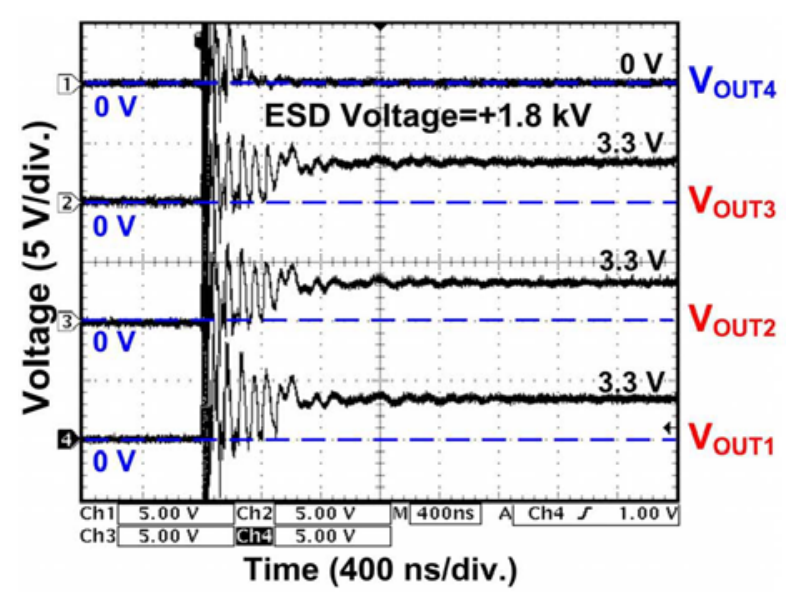

(c)

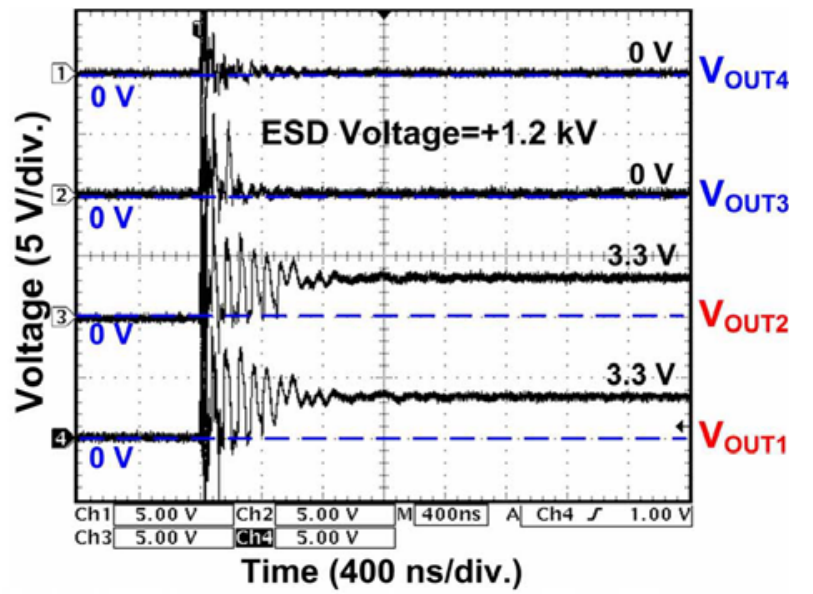

(b)

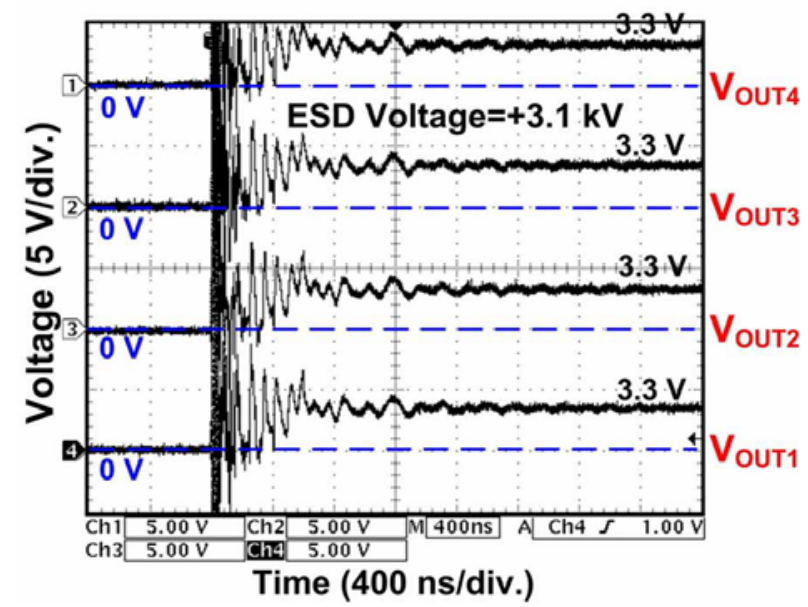

(d)

Fig. 14. Measured $V_{\mathrm{OUT} 1}, V_{\mathrm{OUT} 2}, V_{\mathrm{OUT} 3}$, and $V_{\mathrm{OUT} 4}$ transient voltage waveforms of the proposed on-chip 4-bit transient-to-digital converter under a system-level ESD test with an ESD voltage of (a) $+0.8 \mathrm{kV}$, (b) $+1.2 \mathrm{kV}$, (c) $+1.8 \mathrm{kV}$, and (d) $+3.1 \mathrm{kV}$, zapping on the HCP.

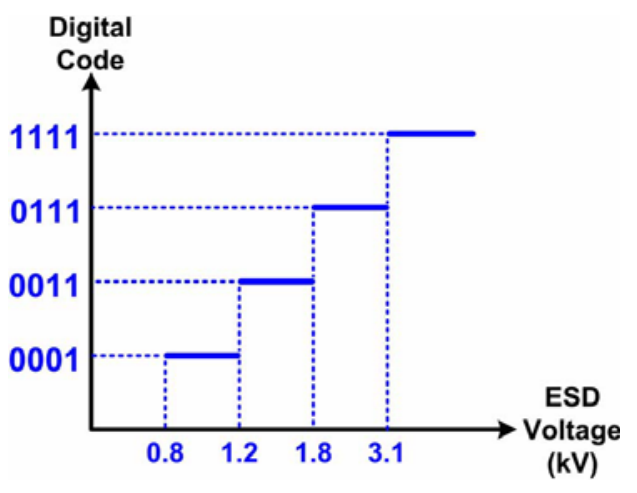

Fig. 15. Relationship between the ESD zapping voltage and the digital code in the proposed transient-to-digital converter.

robustness of CMOS IC products [13]. The proposed on-chip transient-to-digital converter can be further co-designed with firmware to provide a system solution to solve the system-level ESD event to microelectronic products equipped with CMOS ICs.

To realize a system-level ESD protection of a function against upset or freeze after transition, a hardware/firmware co-
TABLE III

ESD Voltage to Digital Code CHARACTERISTIC

\begin{tabular}{|c|c|}
\hline $\begin{array}{c}\text { ESD Voltage } \\
(\mathrm{kV})\end{array}$ & Digital Codes \\
\hline$<0.8$ & 0000 \\
\hline $0.8 \sim 1.2$ & 0001 \\
\hline $1.2 \sim 1.8$ & 0011 \\
\hline $1.8 \sim 3.1$ & 0111 \\
\hline$>3.1$ & 1111 \\
\hline
\end{tabular}

design solution combined with the proposed on-chip transientto-digital converter and the power-ON reset circuit can be built up. Under the normal power-ON condition, the $V_{\mathrm{DD}}$ power-ON voltage waveform has a rise time on the order of a millisecond (ms). The power-ON reset circuit should be designed with the longer rise time on the order of millisecond. Thus, the output signal of the power-ON reset circuit can send the power-on 


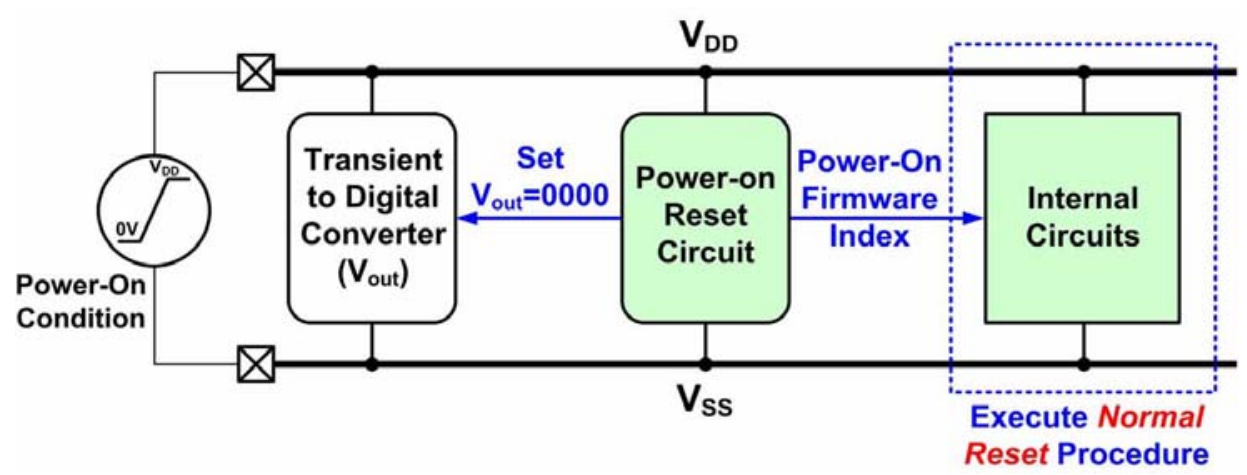

(a)

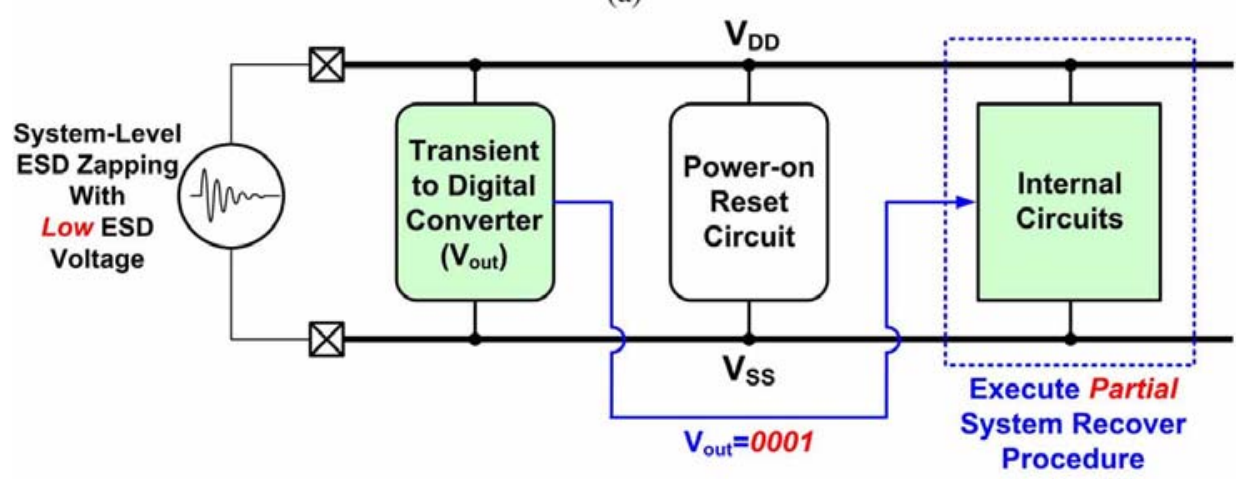

(b)

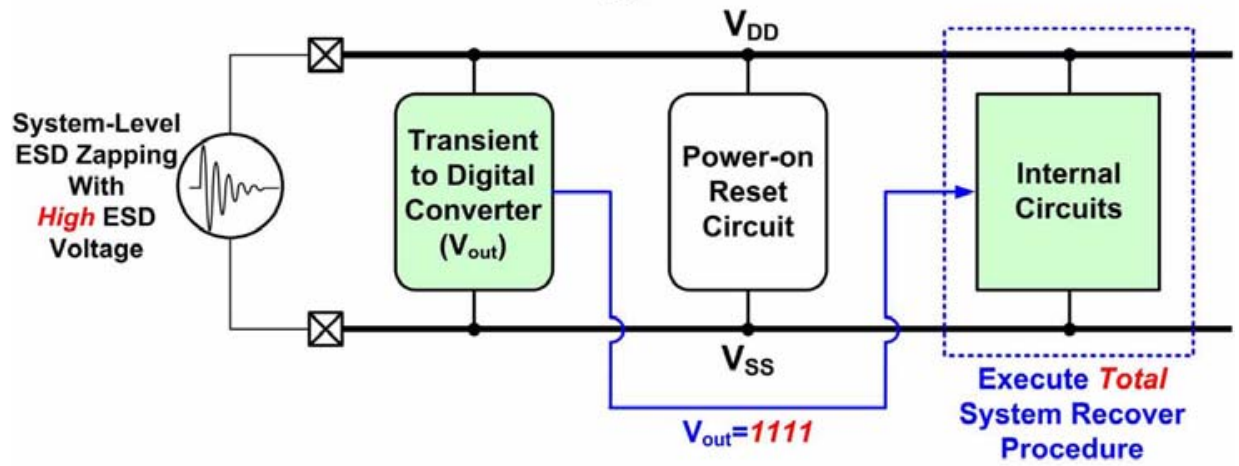

(c)

Fig. 16. Hardware/firmware operation during (a) power-ON reset condition, (b) low system-level ESD zapping, and (c) high system-level ESD zapping.

firmware index for a microelectronic system to execute a normal reset procedure, as shown in Fig. 16(a).

Due to the difference in the rise times between the ESD zapping voltage and the $V_{\mathrm{DD}}$ power-ON voltage, the proposed on-chip transient-to-digital converter is designed to sense fast electrical transients and send different output digital codes under the system-level ESD zapping conditions with different ESD voltages, as shown in Fig. 16(b) and (c). For example, under the system-level ESD zapping with a low ESD voltage, the output digital code of the proposed on-chip transient-to-digital converter becomes "0001." Then, the firmware can execute the partial system recover procedure to check and recover partial electrical functions of microelectronic system. Under the system-level ESD zapping with high enough ESD voltage, the output digital code of the proposed on-chip transient-to-digital converter becomes "1111." Then, the firmware can execute the recover procedure to recover all the electrical functions to a desired stable state as soon as possible. The firmware can be designed to execute different recover procedures with different output digital codes of the proposed on-chip transient-to-digital converter. After the reset and recover procedures, the output digital code of the proposed on-chip transient-to-digital converter is again reset to "0000" for detecting the next transient ESD events.

By including the proposed on-chip transient-to-digital converter and an additional firmware index into the chip, the firmware flowchart shown in Fig. 16(a)-(c) can be used to improve the system-level ESD robustness of microelectronic products. At this moment, different self-recovery procedures based on the proposed transient-to-digital converter under different ESD stress levels have not been supported by simulations or experimental test chips. The output digital codes generated from transient-to-digital converter for using as the firmware index to execute different self-recovery procedures in microelectronic systems will be implemented in some real IC products in the future. 


\section{CONCLUSION}

A novel on-chip transient-to-digital converter composed of four transient detection circuits and four different $R C$ filter networks has been successfully designed and verified in a $0.18-\mu \mathrm{m}$ CMOS process with $3.3-\mathrm{V}$ devices. The detection capability of the on-chip $R C$-based transient detection circuit under the system-level ESD test has been proven by both the experimental results in silicon chip and the HSPICE simulation. The output digital thermometer codes of the proposed transient-todigital converter can successfully correspond to the different ESD voltages under system-level ESD tests. The proposed onchip transient-to-digital converter can be further combined with firmware cooperation to provide an effective solution against upset or freeze malfunctions after system-level ESD zapping on microelectronic systems.

\section{ACKNOWLEDGMENT}

The authors would like to thank Mr. C.-C. Tsai and Dr. T.-Y. Chen for their valuable technical discussions and the project support from Himax Technologies, Inc., Taiwan. The authors would also like to thank the Associate Editor, Dr. A. Duffy, and his reviewers for their valuable suggestions and comments to improve this paper.

\section{REFERENCES}

[1] S. Voldman, ESD: Circuits and Devices. New York: Wiley, 2006.

[2] A. Amerasekera and C. Duvvury, "The impact of technology scaling on ESD robustness and protection circuit design," in Proc. EOS/ESD Symp., 1994, pp. 237-245.

[3] C. Diaz, T. Kopley, and P. Marcoux, "Building-in ESD/EOS reliability for sub-half-micron CMOS processes," in Proc. IEEE Int. Rel. Phys. Symp. (IRPS), 1995, pp. 276-283.

[4] Electrostatic Discharge Sensitivity Testing_Human Body Model(HBM)_Component Level, ESD Association Standard, Test Method ESD STM5.1, 2001.

[5] Electrostatic Discharge Sensitivity Testing-Machine Model (MM)_Component Level, ESD Association Standard, Test Method ESD STM5.2, 1999.

[6] S. Daniel and G. Krieger, "Process and design optimization for advanced CMOS I/O ESD protection devices," in Proc. EOS/ESD Symp., 1990, pp. 206-213.

[7] R. Rountree, "ESD protection for submicron CMOS circuits: Issues and solutions," in IEDM Tech. Dig., 1988, pp. 580-583.

[8] M.-D. Ker, "Whole-chip ESD protection design with efficient VDD-toVSS clamp circuit for submicron CMOS VLSI," IEEE Trans. Electron Devices, vol. 46, no. 1, pp. 173-183, Jan. 1999.

[9] M.-D. Ker and S.-F. Hsu, "Physical mechanism and device simulation on transient-induced latchup in CMOS ICs under system-level ESD test," IEEE Trans. Electron Devices, vol. 52, no. 8, pp. 1821-1831, Aug. 2005.

[10] EMC-Part 4-2: Testing and Measurement Techniques-Electrostatic Discharge Immunity Test, International Standard IEC 61000-4-2, 2001.

[11] N. Shimoyama, M. Tanno, S. Shigematsu, H. Morimura, Y. Okazaki, and K. Machida, "Evaluation of ESD hardness for fingerprint sensor LSIs," in Proc. EOS/ESD Symp., 2004, pp. 75-81.

[12] D. Smith and A. Wallash, "Electromagnetic interference (EMI) inside a hard disk driver due to external ESD," in Proc. EOS/ESD Symp., 2002, pp. 32-36.

[13] M.-D. Ker and Y.-Y. Sung, "Hardware/firmware co-design in an 8-bits microcontroller to solve the system-level ESD issue on keyboard," $\mathrm{Mi}$ croelectron. Rel., vol. 41, no. 3, pp. 417-429, Mar. 2001.

[14] M. Montrose, Printed Circuit Board Design Techniques for EMC Compliance. Piscataway, NJ: IEEE Press, 2000.

[15] M.-D. Ker and S.-F. Hsu, "Evaluation on board-level noise filter networks to suppress transient-induced latchup in CMOS ICs under system-level
ESD test," IEEE Trans. Electromagn. Compat., vol. 48, no. 1, pp. 161171, Feb. 2006.

[16] H. Ott, Noise Reduction Techniques in Electronic Systems, 2nd ed. New York: Wiley, 1988.

[17] M.-D. Ker, C.-C. Yen, and P.-C. Shin, "On-chip transient detection circuit for system-level ESD protection in CMOS integrated circuits to meet electromagnetic compatibility," IEEE Trans. Electromagn. Compat., vol. 50, no. 1, pp. 13-21, Feb. 2008.

[18] M.-D. Ker, C.-S. Liao, and C.-C. Yen, "Transient detection circuit for system-level ESD protection and its on-board behavior with EMI/EMC filters," in Proc. IEEE Int. Symp. Electromagn. Compat. (EMC), 2008.

[19] M.-D. Ker and S.-F. Hsu, "Component-level measurement for transientinduced latch-up in CMOS ICs under system-level ESD considerations," IEEE Trans. Device Mater. Rel., vol. 6, no. 3, pp. 461-472, Sep. 2006.

[20] Electrostatic Discharge Simulator, NoiseKen ESS-2002 \& TC-825R, Noise Laboratory Co., Ltd. Sagamihara, Japan, 2004.

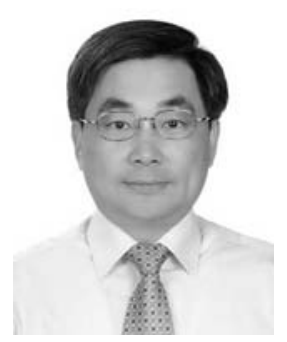

Ming-Dou Ker (S'92-M'94-SM'97-F'08) received the Ph.D. degree from the Institute of Electronics, National Chiao-Tung University, Hsinchu, Taiwan, in 1993.

He was a Department Manager in the Very Large Scale Integration (VLSI) Design Division, Computer and Communication Research Laboratories, Industrial Technology Research Institute (ITRI), Hsinchu, Taiwan. Since 2004, he has been a Full Professor in the Department of Electronics Engineering, National Chiao-Tung University. From 2006 to 2008, he was the Director of Master's Degree Program with the College of Electrical Engineering and Computer Science, National Chiao-Tung University, as well as the Associate Executive Director of National Science and Technology Program on System-on-Chip (NSoC), Taiwan. Since 2008, he has been the Chair Professor and the Vice President of I-Shou University, Kaohsiung, Taiwan, by rotation. In the field of reliability and quality design for circuits and systems in CMOS technology, he has authored or coauthored over 360 technical papers in international journals and conferences. He has proposed many inventions to improve the reliability and quality of ICs, which have been granted with 139 U.S. patents and 144 R.O.C. (Taiwan) patents. He had been invited to teach and/or to consult the reliability and quality design for IC products by hundreds of design houses and semiconductor companies in the worldwide IC industry. His current research interests include reliability and quality design for nanoelectronics and gigascale systems, high-speed and mixed-voltage I/O interface circuits, on-glass circuits for system-on-panel applications, and biomimetic circuits and systems for intelligent prosthesis.

Prof. Ker has served as a member of the Technical Program Committee and the Session Chair of numerous international conferences. He served as an Associate Editor for the IEEE TRANSACTIONS ON VLSI SYSTEMS. He has been selected as a Distinguished Lecturer in the IEEE Circuits and Systems Society (2006-2007) and in the IEEE Electron Devices Society (2008-2009). He was the President of Foundation in Taiwan ESD Association. In 2009, he was awarded as one of the top ten Distinguished Inventors in Taiwan and one of the top 100 Distinguished Inventors in China.

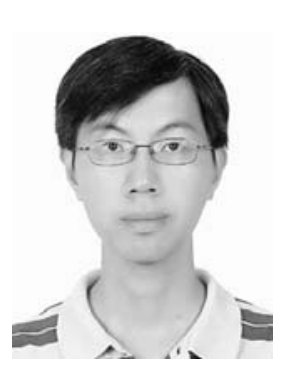

Cheng-Cheng Yen (S'07) received the B.S. degree from the National Chiao-Tung University, Hsinchu, Taiwan, in 1998, and the M.S. degree from the Institute of Electronics, National Chiao-Tung University, where he is currently working toward the Ph.D. degree.

His research interests include transient detection circuits and IC reliability design to meet systemlevel EMC/electromagnetic susceptibility (EMS) regulations. 